\title{
An NMR tool for cyclodextrin selection in enantiomeric resolution by high-performance liquid chromatography
}

\author{
Antonio Laverde Jr, Gelson J. A. da Conceição, Sonia C. N. Queiroz, Fred Y. Fujiwara and \\ Anita J. Marsaioli*
}

Instituto de Química, CP 6154, Universidade Estadual de Campinas, 13083-970, Campinas, SP, Brazil

Received 10 December 2001; Revised 25 March 2002; Accepted 30 March 2002

\begin{abstract}
Complexation-induced chemical shifts and diffusion coefficients (HR-DOSY) of enantiomers with native and derivatized cyclodextrins were used for calculations of the apparent binding constants of three cyclohexanone inclusion complexes. Correlations between these data and high-performance liquid chromatography were established, revealing that this approach can be applied as an alternative method to predict enantiomeric discrimination. Copyright $\left({ }^{\circ} 2002\right.$ John Wiley \& Sons, Ltd.
\end{abstract}

KEYWORDS: NMR; HPLC; HR-DOSY; ${ }^{13} \mathrm{C}$; cyclodextrins; chiral discrimination; diffusion coefficients; enantioseparation

\section{INTRODUCTION}

The past decade has been prolific in enantioselective synthesis, thus leading to an increasing demand for accurate, reliable and convenient methods to assess enantiomeric excesses and to predict enantiomeric discrimination by chiral selectors (CSs). NMR experiments with CSs capable of generating labile diastereomeric species $\left(\mathrm{CSE}_{(+)}\right.$and $\left.\mathrm{CSE}_{(-)}\right)$are necessary to distinguish enantiomers $\left(\mathrm{E}_{(+)}\right.$and $\left.\mathrm{E}_{(-)}\right)$. Complexes (CSE) in a fast equilibrating regime (on the NMR time scale) are recommended due to lineshape broadening. The forces responsible for these associations are known as weak interactions ( $\pi-\pi$ stacking, hydrogen bonds, host-guest interactions). Analytical separation methods for chiral compounds, such as gas chromatography (GC), highperformance liquid chromatography (HPLC), supercritical fluid chromatography (SFC) and capillary electrophoresis (CE), also depend on the same supramolecular interactions in order to achieve enantiodiscrimination. Thus, nothing is more natural than applying NMR experiments to predict chromatographic and CE separations of enantiomers. Indeed this has already been achieved with cyclodextrins (CDs) and derivatives. ${ }^{1}$ The usual methodology is based on the apparent binding constants of each of the enantiomers, determined by titration, which relies on NMR spectroscopic chemical shifts due to complexation. ${ }^{1,2}$ Alternatively, evaluation of the diffusion coefficients in the presence and absence of a CS provides evidence on the magnitude of the binding constants and can be obtained by applying the pulsed-gradient spin-echo (PGSE) methodology.,4 Gafni

*Correspondence to: Anita J. Marsaioli, Instituto de Química, CP 6154, Universidade Estadual de Campinas, 13083-970, Campinas, SP, Brazil. E-mail: anita@iqm.unicamp.br

Contract/grant sponsor: Conselho Nacional de Desenvolvimento

Científico e Tecnológico.

Contract/grant sponsor: Fundação de Amparo à Pesquisa do

Estado de São Paulo. et al. ${ }^{5}$ applied this methodology to calculate the enantiomeric association constants of complexes between enantiomers of arylammonium ions (ephedrine and congeners) and $\beta$ CD. The PGSE methodology can also be extended into a multidimensional format and the experiment results in a twodimensional data set with the diffusion coefficients displayed along one axis and the chemical shifts on the other, termed diffusion ordered spectroscopy (DOSY). ${ }^{4,6}$ These methods are gaining in popularity for the investigation of intermolecular interactions and the determination of binding ratios; these are particularly useful when the host has a much larger molecular volume than the guest, which results in large differences in the diffusion coefficients. ${ }^{7}$ Under a fast exchange regime (NMR time scale), the measured guest's diffusion will be a weighted average of free and bound species, thereby reflecting the equilibrium constant for complex formation. ${ }^{8}$

In this article, a study of the complexes between three cyclohexanone derivatives, 1-3, and six CDs (native and derivatives) has been carried out by NMR spectroscopy, focusing on enantiomeric discrimination (Scheme 1). The aim of this investigation is to recommend a chromatographic chiral phase for a particular application based on NMR parameters. The usual methodology (apparent binding constants by titration) is compared with an alternative method, suggested herein, which correlates enantiomeric discrimination parameters $\left({ }^{13} \mathrm{C}\right.$ NMR-induced chemical shifts) and diffusion coefficients (percent complexed population and apparent binding constants). Reversed-phase (RP) HPLC experiments were carried out to test this methodology.

\section{RESULTS AND DISCUSSION}

\section{Synthesis}

The compounds $( \pm)-\mathbf{1},( \pm)-\mathbf{2}$ and $( \pm)-\mathbf{3}$ were readily available from commercial 2-methyl-1,3-cyclohexanedione (5) 


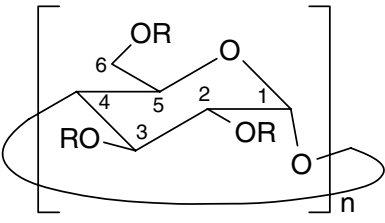

$\mathrm{CD}(\mathrm{PM})$

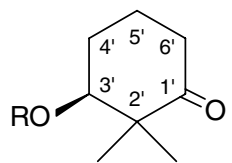

(S)-(+)-1: $\mathrm{R}=\mathrm{H}$

(S)-(+)-2: $\mathrm{R}=\mathrm{COMe}$<smiles>C#CC[C@]1(C)C(=O)CCCC1O</smiles>

$(2 R, 3 S)-(+)-3 a$<smiles>C#CCC1(C)C(=O)CCCC1O</smiles>

$(2 S, 3 S)-(+)-3$

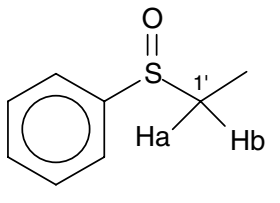

(S)-(-)-4

\section{Scheme 1}
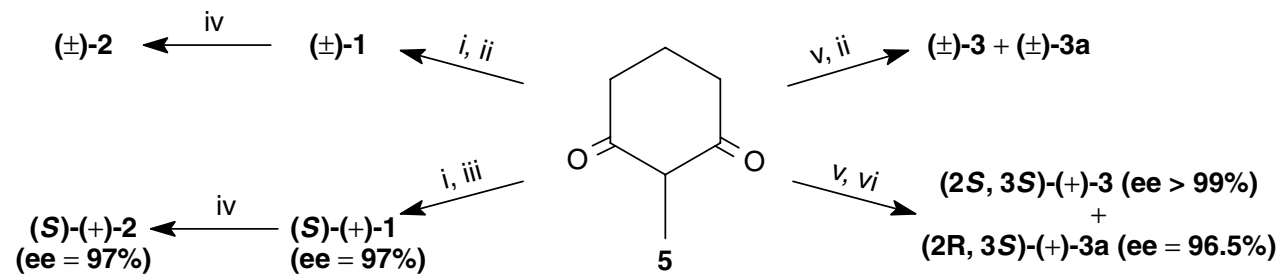

Scheme 2. Reaction conditions: (i) Mel, $t$-BuOK/t-BuOH, $3-4$ days, $60^{\circ} \mathrm{C}$ (85\%); (ii) $\mathrm{NaBH}_{4}, \mathrm{MeOH}, 0^{\circ} \mathrm{C}$ (98\%); (iii) Saccharomyces cerevisiae (72\%); (iv) $\mathrm{Ac}_{2} \mathrm{O}$, Py, ta (99\%); (v) $\mathrm{NaOH}$, Br-propargyl (98\%); (vi) Serratia rubidaea CCT5732, resting cells, 2 days, $28^{\circ} \mathrm{C}$ (60\%).

and the corresponding alkyl halide followed by regioselective reduction with $\mathrm{NaBH}_{4}$ (Scheme 2) and the native CDs were permethylated with MeI. ${ }^{9}$ All compounds were characterized by mass spectrometry (MS), ${ }^{1} \mathrm{H}$ and ${ }^{13} \mathrm{C}$ NMR spectral data and compared with data in the literature. ${ }^{10}$ The enantiomerically pure compounds $(+)-\mathbf{1}$ and $(+)-3$ were obtained by bioreductions of the corresponding ketones (Scheme 2). ${ }^{11}$ The absolute configurations were inferred by comparison of the optical rotations with those in the literature, ${ }^{10 a}$ and the enantiomeric excess (ee) of compounds (+)-2 (97\% ee), (+)-3 (>99\% ee) and (+)-3a (96\% ee) obtained by GC using a chiral column, whereas the ee of (+)-1 was obtained via Feringa's method $\left({ }^{31} \mathrm{P}\right.$ NMR). ${ }^{12}$ The enantiomerically enriched (+)-1, (+)-2 and (+)-3 (ee 33\%) were obtained by mixing the correct amount of racemic and biocatalytically produced alcohols (+)-1 and (+)-3 and derivatized alcohol (+)-2. All experiments were performed with both racemic and enantiomerically enriched mixtures with the purpose of evaluating the apparent binding constants of both enantiomers under absolutely equal experimental conditions.

\section{${ }^{1} \mathrm{H}$ NMR analysis and stoichiometry}

Evaluation of the chemical shift differences of $\mathrm{H}-3$ and H-5 of native and derivatized CDs (both hydrogen atoms inside the cavity), induced by complexation with $( \pm)-\mathbf{1},( \pm)-\mathbf{2}$ and $( \pm)-3$, provided the first information about the host-guest interactions. Accordingly, large chemical shift differences were associated with large binding constants and potentially efficient chiral selection. It was additionally observed that some hydrogen atoms of $( \pm)-\mathbf{1},( \pm)$-2 and $( \pm)$-3 displayed the largest chemical shift differences when complexed with $\beta$-CD. From this preliminary analysis, we have therefore selected this CS as the best for these molecules and chose it for additional experiments.

The stoichiometry of the complexes was determined by using the continuous variation method (Job's method) ${ }^{13}$ as described in the Experimental section. For the sake of concision, some hydrogen atoms of both the guests, $( \pm)-\mathbf{1},( \pm)-\mathbf{2}$ or $( \pm)-\mathbf{3}$, and $\beta$-CD were selected for the experiments, yielding identical results. In all cases, the Job plots (Fig. 1) showed a maximum at $r=0.5$ (where $r=$ [guest] $/($ guest $]+[C D]))$ and symmetrical shapes, indicating that the complexes possessed $1: 1$ stoichiometry.

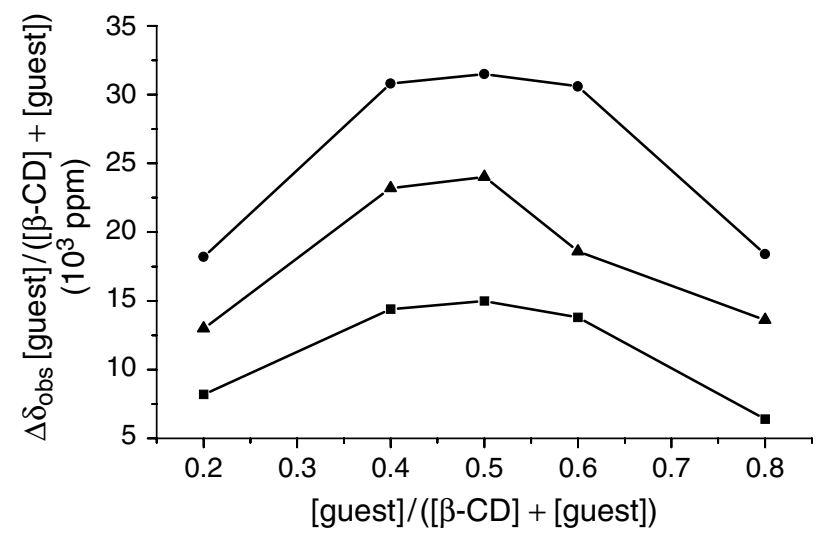

Figure 1. Job plots for complexes: $(\bullet) \beta-\mathrm{CD} /( \pm)-\mathbf{1}$; $(\Delta) \beta-\mathrm{CD} /( \pm)$-2; (口) $\beta$-CD/( \pm$)$-3. 


\section{Apparent binding constants}

The apparent binding constants $K_{\mathrm{ap}}$ were determined by applying the complexation-induced chemical shifts (Benesi-Hildebrand's method) ${ }^{14}$ and Scott's modified equation, which, for a complex of known 1:1 stoichiometry, is: ${ }^{15}$

$$
\frac{[\mathrm{CS}]}{\Delta \delta_{\mathrm{obs}}}=\frac{[\mathrm{CS}]}{\Delta \delta_{\mathrm{c}}}+\frac{1}{K_{\mathrm{ap}} \Delta \delta_{\mathrm{c}}}
$$

[CS] is the equilibrium molar concentration of the CS, $\Delta \delta_{\text {obs }}$ is the observed chemical shift difference for a given [CS], $\Delta \delta_{\mathrm{c}}$ is the difference in the chemical shift of the complex and the free component at saturation. The slope of the plot of [CS] $/ \Delta \delta_{\text {obs }}$ against [CS] for a fixed amount of substrate is thus equal to $1 / \Delta \delta_{c}$ and the intercept with the vertical axis to $1 / K_{\mathrm{ap}} \Delta \delta_{\mathrm{c}}$, which allows the estimation of $K_{\mathrm{ap}}$. The true $\Delta \delta_{\mathrm{c}}$ and $K_{\mathrm{ap}}$ are assessed by successive approximations starting with the total concentration of CS.

The binding constants and the chemical shift differences were calculated for both enantiomers of $( \pm)-\mathbf{1},( \pm)-\mathbf{2}$ and $( \pm)-3$ by measuring the complexation-induced chemical shifts in $2 \mathrm{mmol} \mathrm{l}^{-1}$ solutions of the above-mentioned guests in $\mathrm{D}_{2} \mathrm{O}$ and increasing amounts of $\beta$-CD from 3 to $15 \mathrm{mmol}^{-1}$.

The ${ }^{1} \mathrm{H}$ NMR signals (Fig. 2) of the methyl groups of $( \pm)-2$ at $\delta 0.95$ and $\delta 1.84$, corresponding to the equatorial methyl (i) and acetate methyl (ii) groups respectively, were

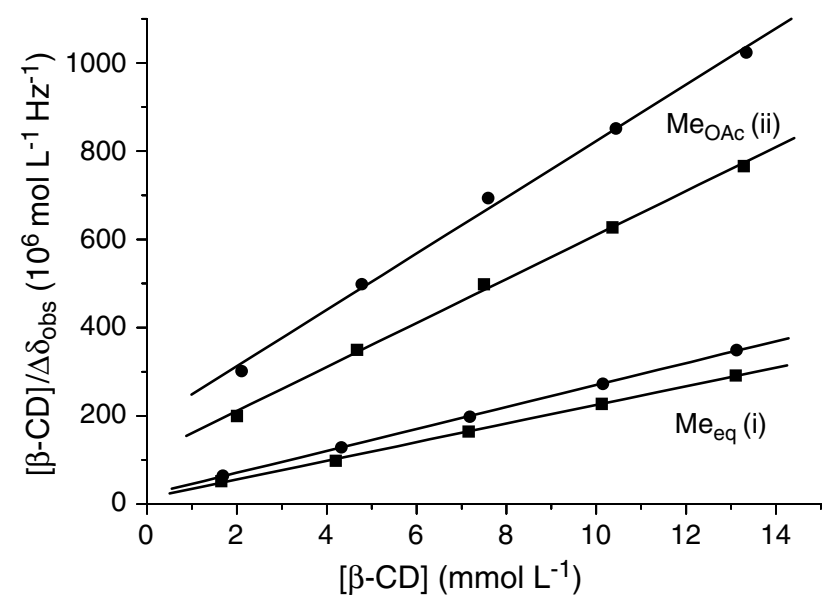

Figure 3. Scott plots of $S-(+)-2(\square)$ and $R-(-)-2(\bullet)$ in solutions with $\beta$-CD.

used for the calculation of the binding constants. The plot of $[\beta-\mathrm{CD}] / \Delta \delta_{\text {obs }}$ versus $[\beta-\mathrm{CD}]$ for the calculation of the binding parameters $\left(K_{\mathrm{ap}(+) \mathrm{i}}, K_{\mathrm{ap}(+) \mathrm{ii}}, K_{\mathrm{ap}(-) \mathrm{i}}, K_{\mathrm{ap}(-) \mathrm{ii}}\right)$ of $( \pm)-2$ with $\beta$-CD is shown in Fig. 3. The choice of different guest hydrogen, atoms among those discriminated by the CS, leads to different binding constant values. Therefore, only the averaged apparent binding constants $\bar{K}_{\text {ap (+) }}$ and $\bar{K}_{\text {ap(-) }}$ are given in Table 1 , together with the corresponding data of $\beta$-CD/( \pm -1, $\beta$-CD/( \pm - -3 and $\beta$-CD/( \pm -4. From these data it was predicted that compounds $\mathbf{2 , 3}$ and $\mathbf{4}$, with larger

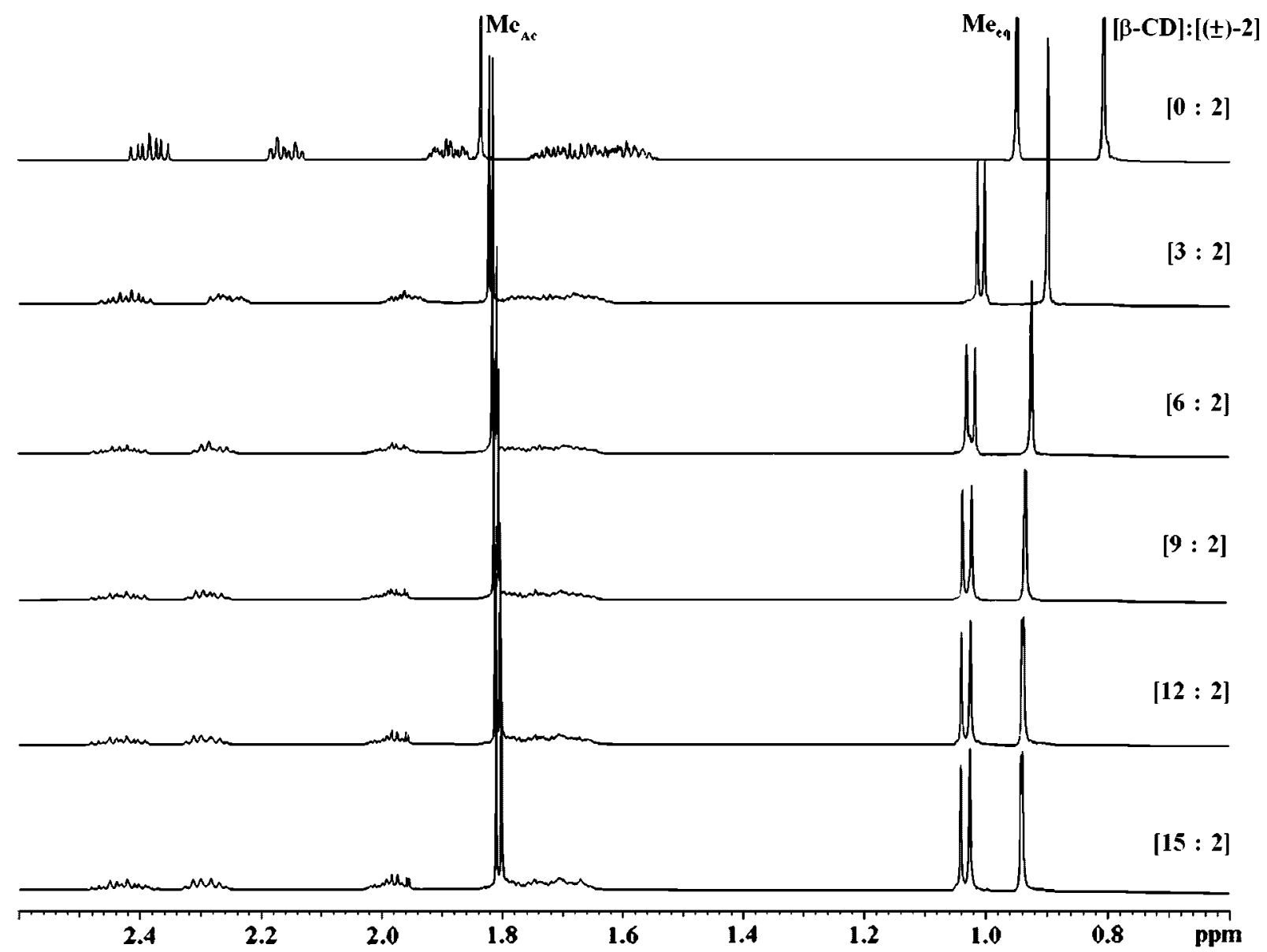

Figure 2. Partial ${ }^{1} \mathrm{H}$ NMR spectra of $( \pm)-2\left(2 \mathrm{mmol} \mathrm{I}^{-1}\right)$ and $\beta$-CD solutions at various concentrations $\left(3,6,9,12\right.$ and $\left.15 \mathrm{mmol} \mathrm{I}^{-1}\right)$. 
Table 1. Apparent binding constants $K_{\mathrm{ap}}$ for the CD induced complexes

\begin{tabular}{|c|c|c|c|c|c|}
\hline \multirow[b]{2}{*}{ Entry } & \multicolumn{5}{|c|}{$K_{\mathrm{ap}}\left(\mathrm{M}^{-1}\right)$} \\
\hline & & $\beta-\mathrm{CD} / \mathbf{1}$ & $\beta-\mathrm{CD} / 2$ & $\beta-\mathrm{CD} / 3$ & $\beta-\mathrm{CD} / 4^{\mathrm{a}}$ \\
\hline 1 & $K_{\mathrm{ap}(+) \mathrm{i}}$ & $260 \pm 16^{\mathrm{b}}$ & $1570 \pm 305^{\mathrm{d}}$ & $1020 \pm 80^{f}$ & $172^{\mathrm{h}}$ \\
\hline 2 & $K_{\mathrm{ap}(+) \mathrm{ii}}$ & $380 \pm 10^{c}$ & $450 \pm 45^{\mathrm{e}}$ & $940 \pm 47^{\mathrm{g}}$ & $340^{\mathrm{i}}$ \\
\hline 3 & $K_{\mathrm{ap}(-) \mathrm{i}}$ & $300 \pm 21^{\mathrm{b}}$ & $1190 \pm 94^{\mathrm{d}}$ & $1345 \pm 95^{f}$ & $166^{\mathrm{h}}$ \\
\hline 4 & $K_{\mathrm{ap}(-) \mathrm{ii}}$ & $400 \pm 10^{c}$ & $350 \pm 37^{\mathrm{e}}$ & $1105 \pm 70^{\mathrm{g}}$ & $254^{\mathrm{i}}$ \\
\hline 5 & $\bar{K}_{\mathrm{ap}(+)^{\mathrm{j}}}$ & $320 \pm 20$ & $1010 \pm 310$ & $980 \pm 90$ & 256 \\
\hline 6 & $\bar{K}_{\mathrm{ap}(-)^{\mathrm{j}}}$ & $350 \pm 24$ & $770 \pm 100$ & $1225 \pm 118$ & 210 \\
\hline 7 & $\alpha$ & $1.10^{\mathrm{k}}$ & $1.31^{1}$ & $1.25^{\mathrm{k}}$ & $1.22^{\mathrm{k}}$ \\
\hline
\end{tabular}

${ }^{\mathrm{a}}$ ref. 16.

$\mathrm{b} \mathrm{i}=\mathrm{H}-3^{\prime}$.

${ }^{\mathrm{c}} \mathrm{ii}=\mathrm{Me}_{\mathrm{ax}}$.

$\mathrm{d}_{\mathrm{i}}=\mathrm{Me}_{\mathrm{eq}}$.

$\mathrm{e}_{\mathrm{ii}}=\mathrm{Me}_{\mathrm{OAc}}$.

${ }^{\mathrm{f}} \mathrm{i}=\mathrm{Me}$.

$\mathrm{g}_{\mathrm{ii}}=\mathrm{H}-\mathrm{9}^{\prime}$.

$\mathrm{h}_{\mathrm{i}}=\mathrm{H}-1 \mathrm{a}^{\prime}$.

${ }^{\mathrm{i}}$ ii $=\mathrm{H}-1 \mathrm{~b}^{\prime}$.

¡ Average value.

${ }^{\mathrm{k}} \alpha=K_{\mathrm{ap}(+)} / K_{\mathrm{ap}(-)}$.

${ }^{1} \alpha=K_{\mathrm{ap}(-)} / K_{\mathrm{ap}(+)}$.

$\bar{K}_{\mathrm{ap}}$, would be better discriminated by RP-chromatography using $\beta$-CD in either the stationary or mobile phases. As the degree of retention of each component is dependent on its interactions with the stationary phase and the mobile phase, the association constants of each enantiomer to the CD chiral phase (either stationary or mobile) is responsible for the enantioseparation. It was further predicted that $(+)-2$ with a larger association constant would be the first enantiomer to elute with $\beta$-CD in the mobile phase and the last with $\beta$-CD in the stationary phase.

\section{Intermolecular nuclear Overhauser enhancement}

Intermolecular nuclear Overhauser enhancements were almost null, owing to the fact that $\omega_{\mathrm{o}} \tau_{\mathrm{c}} \cong 1$ for the complexed species. Therefore, to assess the topologies, nuclear Overhauser enhancements were measured in the rotating frame ${ }^{17}$ using racemic $\mathbf{1}, \mathbf{2}$ and 3 with $C D(1: 1$ ratio and $15 \mathrm{mmol}^{-1}$ each) in $\mathrm{D}_{2} \mathrm{O}$ using 1D-ROESY pulse sequences. Selective pulses were applied on the substrate hydrogen atoms, and detection of ROE effects on inner CD hydrogen atoms ( $\mathrm{H}-3$ and $\mathrm{H}-5)$ were taken as evidence of inclusion complex formation. Results from selective 1D-ROESY experiments and more probable topologies for $\beta-\mathrm{CD} / \mathbf{1}, \beta-\mathrm{CD} / \mathbf{2}$ and $\beta-\mathrm{CD} / \mathbf{3}$ complexes are shown in Fig. 4. Encapsulations of $( \pm)-1,( \pm)-2$ and $( \pm)-3$ in the $\gamma$ $\mathrm{CD}$ were also confirmed by ROEs, but the signals were more influenced by $\beta$-CD, denoting better complexation.

\section{Diffusion coefficients by pulsed field gradient spin echo}

After characterizing the supramolecular interactions responsible for the enantiomeric discrimination by classical methods, the same focus was applied with high-resolution DOSY. The success of this part of our work relied on the choice of the correct pulse sequence and gradients for the experiments. Low-resolution DOSY does not provide well-resolved NMR spectra and it is difficult to obtain clean diffusion coefficients when signals overlap. However, with HR-DOSY, achieved with the choice of the correct pulse sequence, small differences in diffusion coefficients can be resolved (1\%). According to Pelta et al.,18 the gradient-compensated stimulated echo spin lock (GCSTESL) pulse sequence furnishes diffusion data with small standard errors, giving well defined diffusion projection with virtually no peaks at intermediate diffusion values. Two pulse sequences were used in HRDOSY experiments: GCSTESL and BPPSTE ${ }^{19}$ (bipolar pulse pairs stimulated echo). However, reliable diffusion data sets were obtained with the GCSTESL pulse sequence. The bound

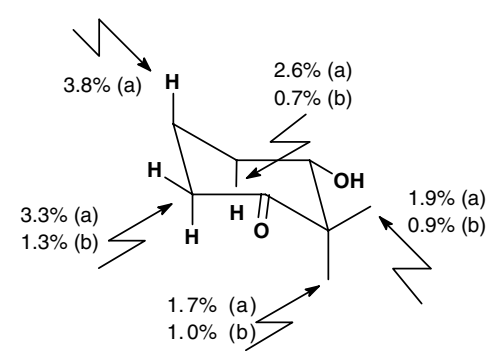

1

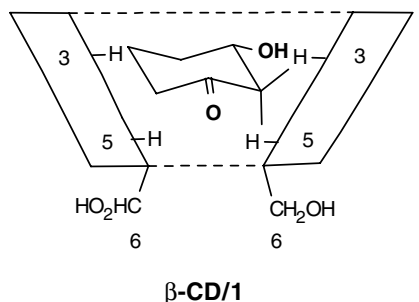

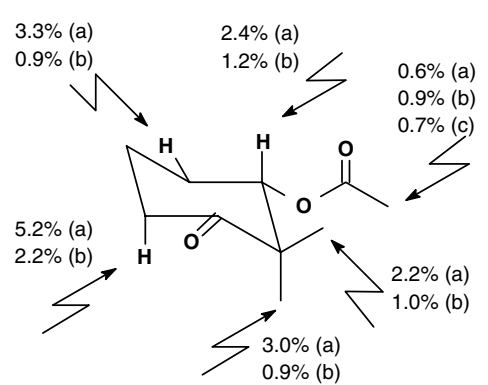

2

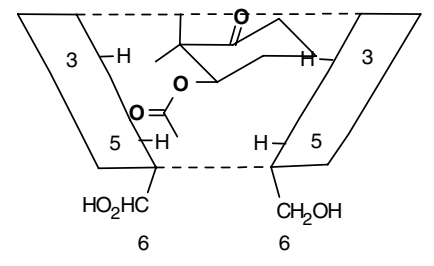

$\beta-C D / 2$
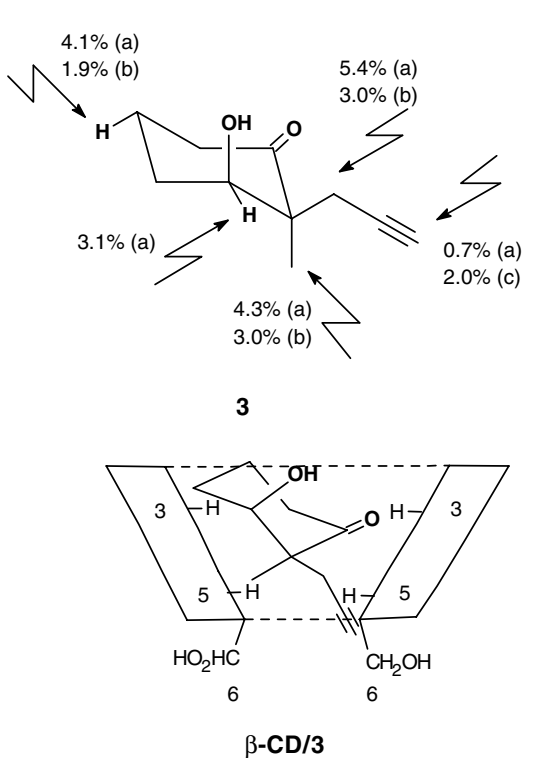

Figure 4. Intermolecular enhancements (\%) of the internal $\beta$-CD hydrogen signals ((a) $\mathrm{H}-3$, (b) $\mathrm{H}-5$ and (c) $\mathrm{H}-6)$ observed in the 1D-ROESY experiments and suggested topologies of the adducts. 
and free guests undergo fast exchange on the diffusion time scale and, therefore, the observed guest diffusion coefficient $D_{\text {obs }}$ is the weighted average of the free solution $D_{\text {free }}$ and CD bound $D_{\text {bound }}$ values, and it is described by: ${ }^{20,21}$

$$
D_{\mathrm{obs}}=\left(1-p_{\mathrm{bound}}\right) D_{\text {free }}+p_{\text {bound }} D_{\text {bound }}
$$

where $p_{\text {free }}+p_{\text {bound }}=1$. Rearranging Eqn (2):

$$
p_{\text {bound }}=\left(D_{\text {free }}-D_{\text {obs }}\right)\left(D_{\text {free }}-D_{\text {bound }}\right)^{-1}
$$

where $p_{\text {free }}$ and $p_{\text {bound }}$ are, respectively, the fractions of free guest and guest bound to CD; $D_{\text {bound }}$ is the diffusion coefficient of the complex and $D_{\text {free }}$ that of the free substrate. The CD diffusion coefficient was almost unaffected upon complexation. $D_{\text {free }}$ of the guest $\left(15 \mathrm{mmol}^{-1}\right)$ was measured separately in the absence of $\mathrm{CD}$ in aqueous solution (Fig. 5a). It can be safely assumed that $D_{\text {free }}$ is the same in the $\mathrm{CD}$ solution, since any obstruction effect due to the $\mathrm{CD}$ is negligible at the low concentrations employed. ${ }^{20}$ The diffusion coefficients of the bound guests could not be measured and were taken to be equal to the diffusion coefficient of $\mathrm{CD}$ measured for the $\mathrm{CD} /$ guest solutions (Fig. 5b), which was assumed to be equal to that of the free CD.

The association binding constants $K_{\mathrm{ap}^{\prime}}$ of all complexes were estimated (Table 2) using the complexed population values previously determined with Eqn. (4): ${ }^{20}$

$$
K_{\mathrm{ap}^{\prime}}=p\left\{(1-p)\left([\mathrm{CD}]_{\mathrm{o}}-p[\mathrm{~S}]_{\mathrm{o}}\right)\right\}^{-1}
$$

where $p$ is $p_{\text {bound }}$ of Eqn (3), and $[S]_{o}$ and $[C D]_{o}$ denote the total concentrations of substrate (guest) and cyclodextrin (host) respectively.

The results confirmed previous NMR experiments that the best CS was the $\beta$-CD and that the order of the apparent binding constants was $K_{\mathrm{ap}^{\prime}} \mathbf{2}>K_{\mathrm{ap}^{\prime}} \mathbf{3}>K_{\mathrm{ap}^{\prime}} \mathbf{1}$ (Table 2, entries 5, 8 and 2 respectively). Therefore, compound 2 should be the most efficiently resolved by chromatography using $\beta$-CD in either the stationary or in the mobile phase. It is worth mentioning that the order of the apparent binding constants $\bar{K}_{\text {ap }}$ obtained by ${ }^{1} \mathrm{H}$ NMR titration for each of the enantiomers was not equal (Table 1), but both the $\alpha$ values (stereoselectivity of complexation) and the apparent binding constants $K_{\mathrm{ap}}$ obtained by diffusion experiments followed the same trend. Thus compound $\mathbf{2}$ was again predicted as the best resolved compound using $\beta-C D$, just as in the previous experiments. Unfortunately, the enantiomeric binding constants could not be determined, in spite of all our efforts, because the resolution of the HR-DOSY was not appropriate to produce enantiomerically discriminated diffusion data.

However, the above experiments point to the applicability of the $K_{\mathrm{ap}^{\prime}}$ obtained in PGSE experiments to predict the discriminating abilities of CD in chromatographic experiments. Measurements of the $K_{\mathrm{ap}^{\prime}}$ in the mixture would significantly reduce the number of experiments. We have indeed performed such experiments, but they will not be discussed here.

\section{${ }^{13} \mathrm{C}$ NMR analysis}

Notwithstanding these satisfactory results, we were aware that the apparent binding constants for each enantiomer were important to distinguish substrates displaying similar diffusion coefficients. In the absence of such data, the difference in the enantiomeric binding constant could be inferred from the discriminated ${ }^{1} \mathrm{H}$ NMR or ${ }^{13} \mathrm{C}$ NMR signals. The latter, with chemical shifts extending over a broader scale, would provide more discriminated signals than ${ }^{1} \mathrm{H}$ NMR. A detailed insight of the complex host-guest backbone is expected from ${ }^{13} \mathrm{C}$ NMR signal splittings that often arise from different encapsulation modes (guest and host backbone modification by diastereomeric complexation).

In our case, the use of enantiomerically enriched guests (33\% ee) allowed the ${ }^{13} \mathrm{C}$ signal assignments for the $(+)$ and (-) enantiomers based on the signal intensities (Fig. 6). Splitting of the CD signals was never observed, denoting the existence of a fast equilibrium between the CD (host) and guests in the bound and free forms. As a rule, the ${ }^{13} \mathrm{C}$ NMR signals of the $(+)$ and (-) enantiomers were randomly deshielded and shielded (Fig. 6), precluding any prediction of the enantiomeric relative elution order in chromatography with this CS.

A bulk parameter on the enantiomeric discrimination was obtained by averaging the absolute values of all complexation-induced ${ }^{13} \mathrm{C}$ NMR chemical shift splittings $\left(\Sigma \Delta \delta_{\mathrm{C}} / n_{\mathrm{C}}\right)$ of guests in the presence of CDs (Table 3$)$. Considering that higher $\Sigma \Delta \delta_{\mathrm{C}} / n_{\mathrm{C}}$ values are indicative of different diastereomeric encapsulation energies and topologies, one could infer that $\beta$-CD is the best CS for compounds $\mathbf{1}$ and 2, whereas $\alpha$-CD and $\alpha$-CDPM (Table 3, entries 7 and 17 respectively) would be better for compound 3 .

\section{HPLC experiments}

With the purpose of selecting the best NMR method to predict enantiomeric discrimination in chromatography, we have compared experimental data of RP-HPLC eluted with $\beta$-CD $\left(15 \mathrm{mmol} \mathrm{l}^{-1}\right)$ in the mobile phase. Compounds $( \pm)-2$ and $( \pm)-3$ were resolved (Table 4$)$, whereas $( \pm)-\mathbf{1}$ and $( \pm)-4$ were not resolved by either the available chiral GC column or by RP-HPLC with a chiral mobile phase.

The NMR parameters $\alpha$, calculated using $\bar{K}_{\text {ap }}$ (Table 1, classical method), and $K_{\mathrm{ap}^{\prime}}$ (Table 2 , diffusion method), predicted a discrimination order of $\mathbf{2}>\mathbf{3}>\mathbf{1}$, and both were consistent with the RP-HPLC experimental results (Table 4). Thus $\alpha\left({ }^{1} \mathrm{H}\right.$ NMR discrimination ratio) values above 1.30 would predict discrimination (Table 1, entry 7) and those below 1.20 would not. The problem was dealing with the borderline $\alpha$ values, like those exhibited by $3(\alpha=1.25$, discriminated in the RP-HPLC experiment) and 4 ( $\alpha=1.22$, not discriminated in the same experiment, presented in Table 4, entries 4 and 6 respectively). The use of an additional parameter playing an important role in depicting the diastereomeric interactions of limiting examples was important, and for this purpose we have selected the average ${ }^{13} \mathrm{C}$ NMR chemical shift splittings $\Sigma \Delta \delta_{\mathrm{C}} / n_{\mathrm{C}}$ (Table 3). A close scrutiny of Table 4 showed that neither the diffusion data nor the $\Sigma \Delta \delta_{\mathrm{C}} / n_{\mathrm{C}}$ alone could explain the discriminating behavior 
(a)

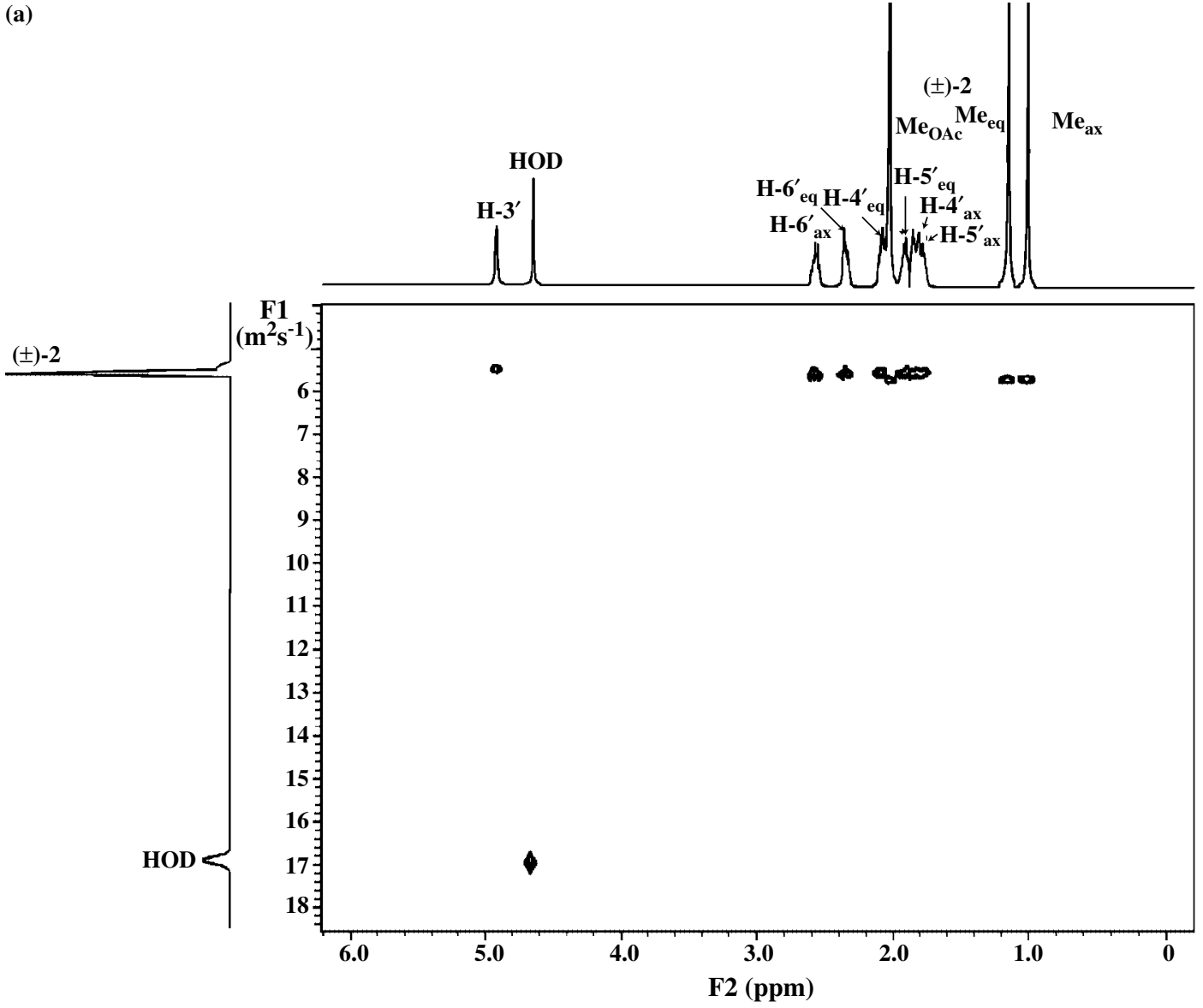

(b)

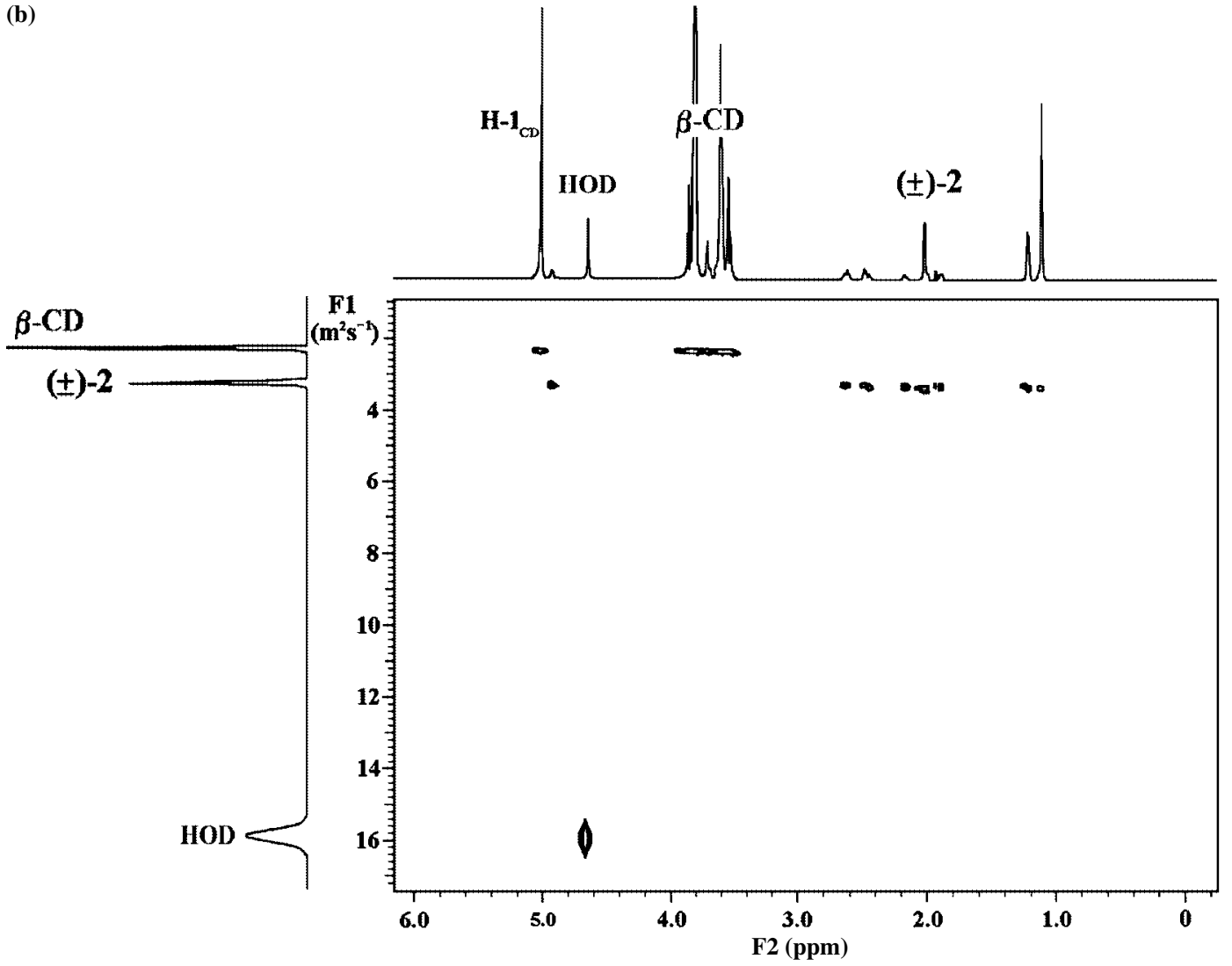

Figure 5. Representative HR-DOSY spectra: (a) pure ( \pm )-2 in $\mathrm{D}_{2} \mathrm{O}\left(15 \mathrm{mmol} \mathrm{I}^{-1}\right)$; (b) complex $\beta$-CD/( \pm )-2 in $\mathrm{D}_{2} \mathrm{O}(15 \mathrm{mmol} \mathrm{I}-1$ each). 
Table 2. Complexed population $p \%$ and apparent bonding constants $K_{\mathrm{ap}}$ calculated from diffusion coefficients of 1-3 and $\mathrm{CD}$ complexes in aqueous solutions $\left(15 \mathrm{mmol} \mathrm{I}^{-1}\right.$ each)

\begin{tabular}{|c|c|c|c|c|c|c|c|}
\hline Entry & Complex & $p(\%)$ & $K_{\mathrm{ap}^{\prime}}\left(\mathrm{M}^{-1}\right)$ & Entry & Complex & $\begin{array}{c}\text { Complexed } \\
\text { population(\%) }\end{array}$ & $K_{\mathrm{ap}^{\prime}}\left(\mathrm{M}^{-1}\right)$ \\
\hline 1 & $\alpha-\mathrm{CD} / \mathbf{1}$ & $17.1 \pm 0.2$ & 17 & 11 & $\alpha-\mathrm{CDPM} / \mathbf{1}$ & $7.2 \pm 1.2$ & 7 \\
\hline 2 & $\beta-\mathrm{CD} / \mathbf{1}$ & $58.7 \pm 1.2$ & 230 & 12 & $\beta-\mathrm{CDPM} / \mathbf{1}$ & $18.4 \pm 1.7$ & 23 \\
\hline 3 & $\gamma-\mathrm{CD} / \mathbf{1}$ & $41.5 \pm 1.1$ & 80 & 13 & $\gamma-\mathrm{CDPM} / \mathbf{1}$ & $6.9 \pm 2.7$ & 7 \\
\hline 4 & $\alpha-\mathrm{CD} / 2$ & $12.6 \pm 1.9$ & 11 & 14 & $\alpha-\mathrm{CDPM} / 2$ & $8.6 \pm 1.7$ & 9 \\
\hline 5 & $\beta-\mathrm{CD} / 2$ & $72.0 \pm 1.4$ & 612 & 15 & $\beta-\mathrm{CDPM} / 2$ & $20.5 \pm 1.7$ & 27 \\
\hline 6 & $\gamma-\mathrm{CD} / 2$ & $46.8 \pm 1.4$ & 110 & 16 & $\gamma-\mathrm{CDPM} / 2$ & $7.6 \pm 1.1$ & 7 \\
\hline 7 & $\alpha-\mathrm{CD} / 3$ & $28.6 \pm 1.9$ & 37 & 17 & $\alpha-\mathrm{CDPM} / 3$ & $25.1 \pm 1.2$ & 37 \\
\hline 8 & $\beta-\mathrm{CD} / 3$ & $65.6 \pm 1.3$ & 370 & 18 & $\beta$-CDPM $/ 3$ & $25.6 \pm 1.3$ & 38 \\
\hline 9 & $\gamma-\mathrm{CD} / 3$ & $43.4 \pm 2.7$ & 90 & 19 & $\gamma-\mathrm{CDPM} / 3$ & $12.4 \pm 1.5$ & 13 \\
\hline $10^{\mathrm{a}}$ & $\beta-\mathrm{CD} / 4$ & $62.2 \pm 1.0$ & 290 & & & & \\
\hline
\end{tabular}

${ }^{\mathrm{a}}$ Ref. 16.

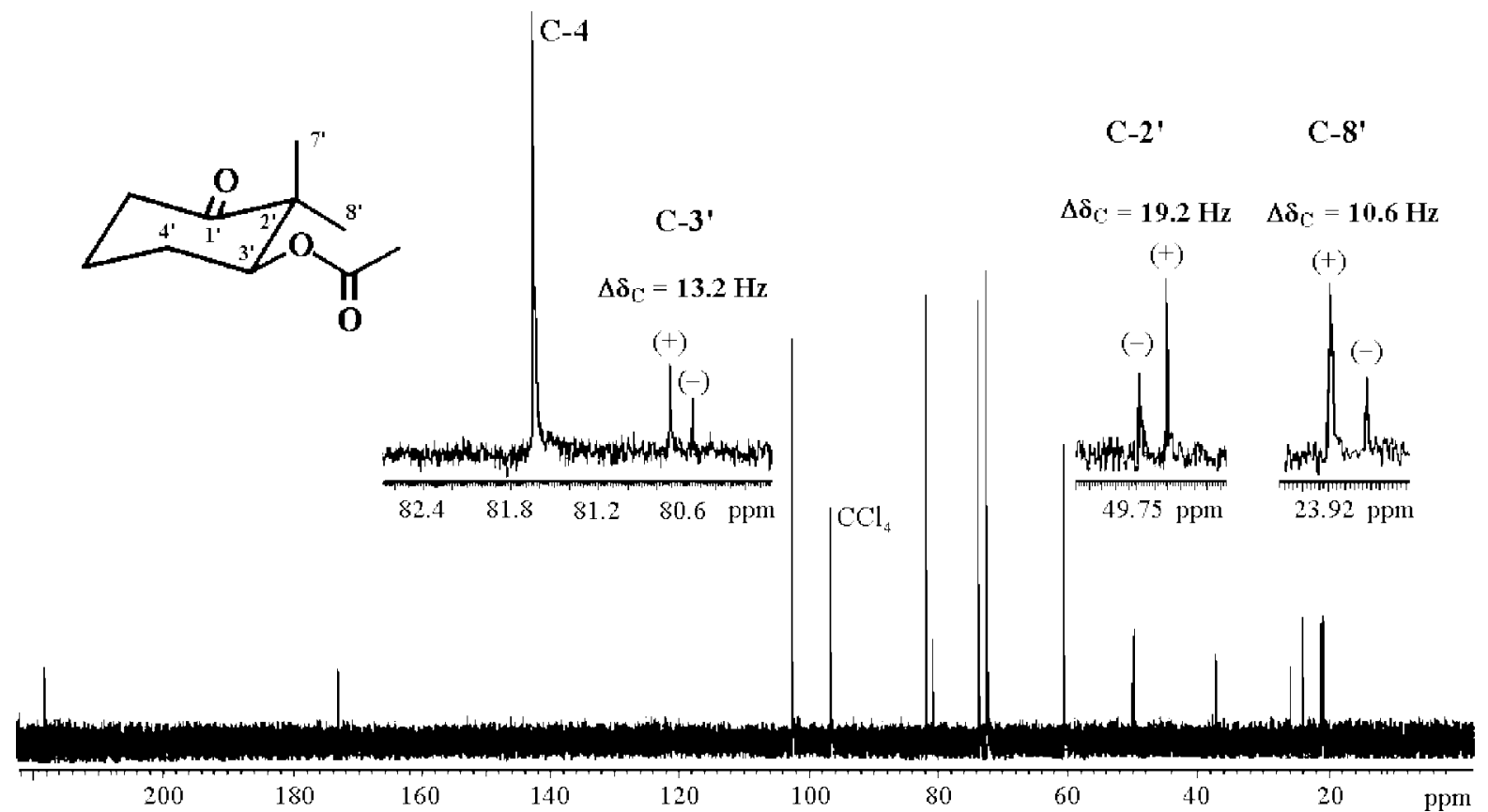

Figure 6. Representative ${ }^{13} \mathrm{C}$ NMR spectrum of an equimolar mixture of $(+)-2$ (ee $\left.33 \%\right)$ and $\beta$-CD (15 mmol I-1 each). The expansions of any discriminated chemical shifts of this substrate show the enantiomer chemical shifts being randomly deshielded and shielded.

and interactions observed in the RP-HPLC experiments. However, use of both $\Sigma \Delta \delta_{\mathrm{C}} / n_{\mathrm{C}}$ and $p \%$ (the percentage of complexed population by diffusion data) produced a set of data that could better explain our experimental results than did only the apparent binding constants (Fig. 7). A $p \%$ above $65 \%$ (Table 2 ) and a large value of $\Sigma \Delta \delta_{\mathrm{C}} / n_{\mathrm{C}}$ (Table 3) would predict a separation of the enantiomers. Thus, $\beta-\mathrm{CD} / 2$ fulfills the required characteristics for good discrimination, i.e. high complexed population percentage (72\%) and large averaged ${ }^{13} \mathrm{C}$ NMR signal splitting value $(11.1 \mathrm{~Hz})$, totally consistent with the experimental observations (Table 4, entry 2). The similarity in the average ${ }^{13} \mathrm{C}$ NMR signal splitting values of $\beta-\mathrm{CD} / \mathbf{1}$ and $\beta-\mathrm{CD} / 3$ (Table 3, entries 2 and 8 respectively) would indicate similar discrimination, but the difference in the apparent binding constants obtained from the diffusion experiments $K_{\mathrm{ap}^{\prime}} \beta-\mathrm{CD} / \mathbf{3}>K_{\mathrm{ap}^{\prime}} \beta-\mathrm{CD} / \mathbf{1}$
(Table 2, entries 8 and 2 respectively) is indeed responsible for the discrimination of 3 in our RP-HPLC experiments. Notwithstanding the good average discrimination of the ${ }^{13} \mathrm{C}$ NMR signals $(9.1 \mathrm{~Hz}), \alpha-\mathrm{CD}$ is not a good chiral selector for 3 (Table 4, entry 3 ) due to both a small $K_{\text {ap' }}$ (Table 2, entry 7) and a low complexed population percentage (Fig. 7). The same is true for 4 , which has a large $K_{\text {ap' }}$ (Table 2, entry 10) but a small $\Sigma \Delta \delta_{\mathrm{C}} / n_{\mathrm{C}}$ (Table 3, entry 10).

\section{Conclusions}

The combination of two favorable factors, the enantiomeric discrimination of ${ }^{13} \mathrm{C}$ NMR signals induced by CD complexation and the apparent binding constants obtained by diffusion experiments with pulsed field gradients (HRDOSY), were used to established an alternative method to predict enantiomeric discrimination by RP-HPLC. Finally, 
Table 3. Complexation-induced ${ }^{13} \mathrm{C}$ NMR chemical shift splittings $\left(\Sigma \Delta \delta_{\mathrm{C}} / n_{\mathrm{C}}\right)$ of compounds $\mathbf{1 - 3}$ diastereomerically complexed by various CDs

\begin{tabular}{ccc}
\hline Entry & Complex & $\begin{array}{c}\Sigma \Delta \delta_{C} / n_{C}{ }^{a} \\
(H z)\end{array}$ \\
\hline 1 & $\alpha-C D / \mathbf{1}$ & 0.1 \\
2 & $\beta-C D / \mathbf{1}$ & 4.6 \\
3 & $\gamma-C D / \mathbf{1}$ & 0.3 \\
4 & $\alpha-C D / 2$ & 0.8 \\
5 & $\beta-C D / 2$ & 11.1 \\
6 & $\gamma-C D / 2$ & 1.9 \\
7 & $\alpha-C D / 3$ & 9.1 \\
8 & $\beta-C D / 3$ & 4.6 \\
9 & $\gamma-C D / 3$ & 3.4 \\
$10^{b}$ & $\beta-C D / 4$ & 2.7 \\
11 & $\alpha-C D P M / \mathbf{1}$ & 0.3 \\
12 & $\beta-C D P M / \mathbf{1}$ & 0.6 \\
13 & $\gamma-C D P M / \mathbf{1}$ & 0.0 \\
14 & $\alpha-C D P M / 2$ & 1.1 \\
15 & $\beta-C D P M / 2$ & 2.4 \\
16 & $\gamma-C D P M / 2$ & 0.0 \\
17 & $\alpha-C D P M / 3$ & 9.5 \\
18 & $\beta-C D P M / 3$ & 5.3 \\
19 & $\gamma-C D P M / 3$ & 0.7 \\
\hline
\end{tabular}

${ }^{a} \Sigma\left|\delta_{\mathrm{C}(+)}-\delta_{\mathrm{C}(-)}\right| / n_{\mathrm{C}}$, where $n_{\mathrm{C}}$ is the number of carbon atoms of substrate.

${ }^{b}$ Ref. 16

we believe that this method might also predict enantiomeric discrimination in chiral CE and in GC.

\section{EXPERIMENTAL}

\section{Methods}

NMR spectroscopy

${ }^{1} \mathrm{H}$ and ${ }^{13} \mathrm{C}$ NMR spectra were obtained on a $11.7 \mathrm{~T}$ Varian Inova-500 spectrometer with standard pulse sequences operating at $499.885 \mathrm{MHz}$ and $125.695 \mathrm{MHz}$ for ${ }^{1} \mathrm{H}$ and ${ }^{13} \mathrm{C}$

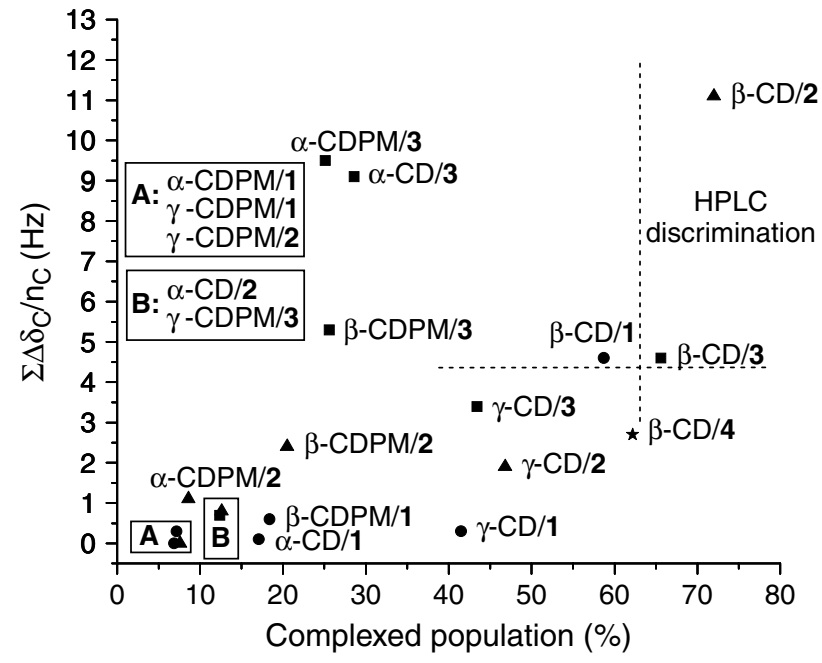

Figure 7. Diagram of the average ${ }^{13} \mathrm{C}$ chemical shift difference between both diastereomeric complexed species $\left(\Sigma \Delta \delta_{\mathrm{C}} / n_{\mathrm{C}}\right)$ as a function of complexed population (HR-DOSY).

Complexes: $(\bullet) \mathrm{CD}(\mathrm{PM}) / \mathbf{1} ;(\boldsymbol{\Delta}) \mathrm{CD}(\mathrm{PM}) / \mathbf{2} ;(\mathbf{\square}) \mathrm{CD}(\mathrm{PM}) / \mathbf{3} ;(\star)$ $\mathrm{CD}(\mathrm{PM}) /$. $^{16}$

respectively. The chemical shifts are reported in parts per million using TMS in $\mathrm{CCl}_{4}(\delta 0)$ as an external reference (Job and Scott experiments), or HDO signal ( $\delta 4.67)$ as an internal reference (other experiments) for ${ }^{1} \mathrm{H}$ and $\mathrm{CCl}_{4}(\delta 96.0)$ for ${ }^{13} \mathrm{CNMR}$ spectra. Pulses of $30^{\circ}$ and $45^{\circ}$, and repetition times of $3.8 \mathrm{~s}$ and $2.8 \mathrm{~s}$ for ${ }^{1} \mathrm{H}$ and ${ }^{13} \mathrm{C}$ respectively were used. The coupling constants $J$ are in $\mathrm{Hz}$. All data were obtained at $30.0 \pm 0.1{ }^{\circ} \mathrm{C}$.

The 1D-ROESY experiments were obtained starting with a selective $180^{\circ}$ and a non-selective $90^{\circ}$ pulse, and a mixing time of $500 \mathrm{~ms}$ was used during the spin lock. The selective pulses were generated by a pulse modulator that automatically attenuates the shape, power, and pulse duration to obtain the required selectivity. The subtraction of the on-resonance and off-resonance acquisition furnished the 1D-ROESY experiment.

HR-DOSY experiments were carried out by carefully choosing the correct pulse sequence and gradients for the

Table 4. Results of the RP-HPLC enantioseparation of substrates with various native CDs (chiral mobile phase)

\begin{tabular}{ccccccc}
\hline Entry & $\begin{array}{c}\text { Mobile } \\
\text { phase }\end{array}$ & Compound & $t_{1}(\mathrm{~min})^{\mathrm{a}}$ & $t_{2}(\mathrm{~min})^{\mathrm{a}}$ & $\alpha_{\text {rel }^{\mathrm{b}}}$ & $R_{\mathrm{s}}{ }^{\mathrm{c}}$ \\
\hline 1 & $\beta$-CD & $(+)-\mathbf{1}^{\mathrm{d}}$ & 13.69 & - & - & - \\
2 & $\beta-\mathrm{CD}$ & $(+) \mathbf{2}^{\mathrm{d}}$ & $9.27(+)$ & $11.57(-)$ & 1.33 & 1.10 \\
3 & $\alpha-\mathrm{CD}$ & $( \pm)-3$ & 62.40 & - & - & - \\
4 & $\beta-\mathrm{CD}$ & $(+)-3^{\mathrm{d}}$ & $23.19(-)$ & $24.76(+)$ & 1.08 & 0.86 \\
5 & $\gamma-\mathrm{CD}$ & $( \pm)-3$ & 30.99 & - & - & - \\
$6^{\mathrm{e}}$ & $\beta-\mathrm{CD}$ & $( \pm)-4$ & 56.51 & - & - & - \\
\hline
\end{tabular}

${ }^{\mathrm{a}} t_{1}$ and $t_{2}$ are retention time of enantiomers.

b Selectivity of enantioseparation is $\alpha_{\text {rel }}=k_{2} / k_{1}$, where $k_{n}=\left(t_{n}-t_{M}\right)\left(t_{M}\right)^{-1}$ and $t_{M}$ is the baseline shift due to the injection solvent.

${ }^{\mathrm{c}}$ Resolution of enantiomers is $R_{\mathrm{s}}=1.177\left(t_{2}-t_{1}\right)\left(w_{\mathrm{h} 1}+w_{\mathrm{h} 2}\right)^{-1} ; w_{\mathrm{h} n}$ is half-maximum intensity line enantiomer width.

${ }^{\mathrm{d}} \mathrm{Ee} \approx 33 \%$.

e Ref. 16. 
experiments. The measurements were made using: (a) a $5 \mathrm{~mm}$ inverse probe with a $z$-gradient coil; (b) the GCSTESL ${ }^{18}$ HR-DOSY sequence; (c) $15 \mathrm{mmol}^{-1}$ solutions of host and guest at $30.0 \pm 0.1{ }^{\circ} \mathrm{C}$; (d) the pulse width was $4 \mathrm{~ms}$ and the spectral width was typically $4200 \mathrm{~Hz}$ and the free induction decays contained $64 \mathrm{~K}$ data points; (e) for all experiments, 25 spectra (32 transients each) were collected with gradient pulse amplitudes ranging from 0.000685 to $0.003427 \mathrm{~T} \mathrm{~cm}^{-1}$, where an approximately $100 \%$ decrease in the resonance intensity was achieved at the largest gradient amplitudes. The baselines of all arrayed spectra were corrected prior to processing the data. After data acquisition, each FID was apodized with $3.0 \mathrm{~Hz}$ line broadening and Fourier transformed. The processing program (the DOSY macro in a Varian instrument) involves the determination of the peak heights of all signals above a pre-established threshold and the fitting of the decay curve for each peak to a Gaussian function. The DOSY macro was run with data transformed using $f_{n}=64 \mathrm{~K}$. Very crowded spectra were processed in sections due to the limitation of handling only 512 lines at a time. The results of the DOSY method of analysis are pseudo two-dimensional spectra with NMR chemical shifts along one axis and calculated diffusion coefficients $\left(\mathrm{m}^{2} \mathrm{~s}^{-1} \times 10^{-10}\right)$ along the other.

The stoichiometry of host-guest complexes was determined by the continuous variation method. ${ }^{13}$ The total concentration of the interacting species in the solution was kept constant at $15 \mathrm{mmol}^{-1}$ and the molar fraction $r$ of the guest was varied in the range 0.2-0.8. Apparent binding constants of the enantiomers of $( \pm)-\mathbf{1},( \pm)-\mathbf{2}$ and $( \pm)-\mathbf{3}$ with $\beta$-CD were calculated on the basis of Scott's modification of the Benesi-Hildebrand equation. ${ }^{14}$

\section{Chiral chromatography}

HPLC chromatograms were obtained with an HP $1090 \mathrm{M}$ LC system, which consisted of a ternary gradient pump, a thermostatic compartment and a diode array detector (DAD). For single wavelength analyses the DAD was set at 200-210 nm with a bandwidth of $10 \mathrm{~nm}$, whereas absorbance spectra were recorded from 200 to $400 \mathrm{~nm}$. The HPLC analyses were carried out using a Waters Nova Pack ODS $(4 \mu \mathrm{m}, 150 \mathrm{~mm} \times 3.9 \mathrm{~mm}$ i.d) column eluted with chiral mobile phase $\left(15 \mathrm{mmol}^{-1}\right) \beta$-CD in at a flow rate of $0.5 \mathrm{ml} \mathrm{min} \mathrm{m}^{-1}$ and a column temperature of $30^{\circ} \mathrm{C}$. The injection volume was $2.0 \mu \mathrm{l}$ of a solution with about $10 \mathrm{mg} \mathrm{ml}^{-1}$ of the mixture in water.

GC-MS analyses were carried out using an HP-5990/5970 system equipped with an HP-5 fused silica capillary column $(30 \mathrm{~m} \times 0.25 \mathrm{~mm} \times 0.25 \mu \mathrm{m})$; column temperatures were programmed from 80 to $290{ }^{\circ} \mathrm{C}$ at $15{ }^{\circ} \mathrm{C} \mathrm{min}^{-1}$. GC-MS injector and detector temperatures were $220^{\circ} \mathrm{C}$ and $285{ }^{\circ} \mathrm{C}$ respectively; the flow rate of helium was $1.16 \mathrm{ml} \mathrm{min}^{-1}$. The injection volume, $0.5 \mu \mathrm{l}$ of a solution of about $10 \mathrm{mg} \mathrm{ml}^{-1}$ of the mixture in ethyl acetate, was in split mode. The mass spectra were determined at $70 \mathrm{eV}$. Scanning speed was 0.84 scan s $^{-1}$ from $m / z 40$ to 550 .

Chiral GC analyses were carried out using a GC(FID) HP5890 chromatograph, equipped with a heptakis-(2,6-methyl3 -pentyl)- $\beta$-cyclodextrin chiral column $(25 \mathrm{~m} \times 0.25 \mathrm{~mm} \times$
$0.25 \mu \mathrm{m})$. Injector and detector temperatures were $200{ }^{\circ} \mathrm{C}$. The temperature program was: $90{ }^{\circ} \mathrm{C}, 5 \mathrm{~min} / 3{ }^{\circ} \mathrm{C} \mathrm{min}^{-1} /$ $180{ }^{\circ} \mathrm{C}, 5 \mathrm{~min}$. Pressure at the head of the column was 0.6 bar.

Optical rotations were measured with a LEP A2 (Carl Zeiss) polarimeter, equipped with a sodium lamp $\left(0.005^{\circ}\right.$ precision), at $20{ }^{\circ} \mathrm{C}$ and expressed as $[\alpha]_{\mathrm{D}}^{20}$ (concentrations in grams $/ 100 \mathrm{ml}$, solvent).

\section{Synthesis}

Chemicals and reagents

$\alpha$-CD (98\%), $\beta$-CD (98\%) and $\gamma$-CD $(98 \%)$ were purchased from Acros Organics, Merck and Wacker Chemicals respectively. The permethylated CDs were obtained according to a procedure described in the literature. ${ }^{9}$ The CDs were lyophilized prior to the preparation of solutions for NMR spectroscopy. Racemic and pure substrates were synthesized in our laboratory as described below. All NMR samples $(0.6 \mathrm{ml})$ were prepared in $\mathrm{D}_{2} \mathrm{O}, 99.9 \%$ (Aldrich).

(S)-(+)-3-Hydroxy-2,2-dimethylcyclohexan-1-one, (+)-1

The syntheses of $(+)-\mathbf{1}$ and $( \pm)-\mathbf{1}$ have been previously reported. ${ }^{12}$

Spectroscopic data of $(+)-\mathbf{1}: \delta_{\mathrm{H}}\left(500 \mathrm{MHz} ; \mathrm{D}_{2} \mathrm{O} ; \mathrm{HOD}\right) 1.04(3 \mathrm{H}$, $\left.\mathrm{s}, \mathrm{Me}_{\mathrm{ax}}\right), 1.11\left(3 \mathrm{H}, \mathrm{s}, \mathrm{Me}_{\mathrm{eq}}\right), 1.68\left(1 \mathrm{H}, \mathrm{m}, \mathrm{H}-5_{\mathrm{ax}}^{\prime}\right), 1.79\left(1 \mathrm{H}, \mathrm{m}, \mathrm{H}-4_{\mathrm{ax}}^{\prime}\right)$, $1.92\left(1 \mathrm{H}, \mathrm{m}, \mathrm{H}-5_{\mathrm{eq}}^{\prime}\right), 2.05\left(1 \mathrm{H}, \mathrm{m}, \mathrm{H}-4_{\mathrm{eq}}^{\prime}\right), 2.39(1 \mathrm{H}, \mathrm{ddd}, J$ 5.8, 7.6 and 14.8, H- $\left.6_{\mathrm{ax}}^{\prime}\right), 2.46\left(1 \mathrm{H}, \mathrm{ddd}, J 5.8,8.0\right.$ and $\left.14.8, \mathrm{H}-6_{\mathrm{eq}}^{\prime}\right), 3.75(1 \mathrm{H}$, $\mathrm{dd}, J 3.4$ and 7.4, H-3' $) ; \delta_{\mathrm{C}}\left(125 \mathrm{MHz} ; \mathrm{D}_{2} \mathrm{O} ; \mathrm{CCl}_{4}\right) 19.02\left(\mathrm{Me}_{\mathrm{ax}}\right), 19.99$ $\left(\mathrm{C}-5^{\prime}\right), 22.15\left(\mathrm{Me}_{\mathrm{eq}}\right), 27.39\left(\mathrm{C}-4^{\prime}\right), 36.78\left(\mathrm{C}-6^{\prime}\right), 50.87\left(\mathrm{C}-2^{\prime}\right), 77.29\left(\mathrm{C}-3^{\prime}\right)$, $221.77\left(\mathrm{C}-1^{\prime}\right)$.

(S)-(+)-3-Acetoxy-2,2-dimethylcyclohexan-1-one, $(+)-2$

A solution of $(+)-1(30.0 \mathrm{mg}, 0.21 \mathrm{mmol})$ in pyridine $(1.0 \mathrm{ml})$ was treated with acetic anhydride $(1.0 \mathrm{ml})$. The mixture was stirred at room temperature for $20 \mathrm{~h}$. Usual work-up and purification yielded (+)-2 as a viscous oil (34.8 $\mathrm{mg}, 98 \%$ yield).

$[\alpha]_{\mathrm{D}}^{20}=+10.7\left(c 1.87\right.$ in $\left.\mathrm{CHCl}_{3}\right) ; v_{\max }(\mathrm{film}) / \mathrm{cm}^{-1} 2952,1740$, $1713,1374,1240,1045,988 ; m / z: 184\left(\mathrm{M}^{+}, 8 \%\right), 142$ (12), 124 (20), 82 (45), 55 (22), $43(100) ; \delta_{\mathrm{H}}\left(500 \mathrm{MHz} ; \mathrm{D}_{2} \mathrm{O}\right.$; HOD) $1.02\left(3 \mathrm{H}, \mathrm{s}, \mathrm{Me}_{\mathrm{ax}}\right)$, $1.17\left(3 \mathrm{H}, \mathrm{s}, \mathrm{Me}_{\mathrm{eq}}\right), 1.80\left(1 \mathrm{H}, \mathrm{m}, \mathrm{H}-5_{\mathrm{ax}}^{\prime}\right), 1.86\left(1 \mathrm{H}, \mathrm{m}, \mathrm{H}-4_{\mathrm{ax}}^{\prime}\right), 1.92(1 \mathrm{H}$, m, H-5 $\left.5_{\text {eq }}^{\prime}\right), 2.05\left(3 \mathrm{H}, \mathrm{s}, \mathrm{Me}_{\mathrm{Ac}}\right), 2.11\left(1 \mathrm{H}, \mathrm{m}, \mathrm{H}-4_{\mathrm{eq}}^{\prime}\right), 2.38(1 \mathrm{H}, \mathrm{dtd}, J$ $1.2,5.7$ and 15.1, H-6 $\left.6_{\mathrm{ax}}^{\prime}\right) ; 2.60\left(1 \mathrm{H}, \mathrm{ddd}, J 6.1,9.8\right.$ and 15.1, $\left.\mathrm{H}-6_{\mathrm{eq}}^{\prime}\right)$, $4.94\left(1 \mathrm{H}, \mathrm{dd}, J 3.1\right.$ and $\left.6.0, \mathrm{H}-3^{\prime}\right) ; \delta_{\mathrm{C}}\left(125 \mathrm{MHz} ; \mathrm{D}_{2} \mathrm{O} ; \mathrm{CCl}_{4}\right) 19.31$ $\left(\mathrm{Me}_{\mathrm{ax}}\right), 20.10\left(\mathrm{Me}_{\mathrm{Ac}}\right), 20.14\left(\mathrm{C}-5^{\prime}\right), 22.49\left(\mathrm{Me}_{\mathrm{eq}}\right), 24.58\left(\mathrm{C}-4^{\prime}\right), 36.72$ $\left(\mathrm{C}-6^{\prime}\right), 49.13\left(\mathrm{C}-2^{\prime}\right), 80.55\left(\mathrm{C}-3^{\prime}\right), 173.45\left(\mathrm{CO}_{\mathrm{Ac}}\right), 220.34\left(\mathrm{C}-1^{\prime}\right)$.

Enantiomeric excess was determined by chiral GC $(97 \%$ ee). The compound $( \pm)-2$ was obtained under identical conditions $(98 \%$ yield) and presented the same spectral data as the enantiomerically pure $(+)-2$.

\section{$(S, S)-(+)-3-H y d r o x y-2-m e t h y l-2-(2-p r o p y n y l)$}

cyclohexan-1-one, $(+)-3$

The bacterium $S$. rubidaea CCT5732 was obtained from the Culture Collection, Fundação de Pesquisa e Tecnologia André Tosello (Brazil). The microorganism was grown at $48 \mathrm{~h} / 28^{\circ} \mathrm{C} / 120 \mathrm{rpm}$ in culture shaker-flasks in an appropriate medium (nutrient broth) and cells were harvest by centrifugation. The reduction of the 2-methyl-2-(2-propynyl)cyclohexane-1,3-dione, was performed in $125 \mathrm{ml}$ bottles on a rotatory shaker $(120 \mathrm{rpm})$. To bottles containing pH7.0 phosphate buffer $(25 \mathrm{ml})$ and washed cells $(350 \mathrm{mg})$, the dione substrate was added $(60 \mathrm{mg}, 0.36 \mathrm{mmol})$. The mixture was shaken at $28{ }^{\circ} \mathrm{C}$ and the reaction was monitored by chiral GC. Upon reaching the appropriate conversion degree, the cells were filtered and the product formed was extracted from the supernatants with ethyl acetate. The organic layer was dried over $\mathrm{Na}_{2} \mathrm{SO}_{4}$, filtered and evaporated under reduced pressure. The residue (oil) was purified by column chromatography on silica gel, eluted with hexane, yielding $(S, S)-(+)$-3-hydroxy-2-methyl-2-(2-propynyl)cyclohexan-1-one, $(+)-3$ (18 $\mathrm{mg}, 27 \%$ yield) and $(R, S)-(+)-3-h y d r o x y-2-m e t h y l-2-(2-$ propynyl)cyclohexan-1-one, (+)-3a (21 mg, 33\% yield).

Data for $(+)-3:[\alpha]_{\mathrm{D}}^{20}=+7.2\left(\right.$ c 6.0 in $\left.\mathrm{CHCl}_{3}\right) ; v_{\max }($ film $) / \mathrm{cm}^{-1}$ 3450, 3291, 2945, 2114, 1704, 1458, 1125, 995; m/z $166\left(\mathrm{M}^{+}, 17 \%\right)$, 122 (39), 109 (90), 107 (43), 106 (29), 95 (80), 93 (84), 91 (100), $77(35), 43(38) ; \delta_{\mathrm{H}}\left(500 \mathrm{MHz} ; \mathrm{D}_{2} \mathrm{O} ; \mathrm{HOD}\right) 1.25\left(3 \mathrm{H}, \mathrm{s}, \mathrm{Me}_{\mathrm{ax}}\right)$, $1.78\left(1 \mathrm{H}, \mathrm{m}, \mathrm{H}-5_{\mathrm{ax}}^{\prime}\right), 1.81\left(1 \mathrm{H}, \mathrm{m}, \mathrm{H}-4_{\mathrm{ax}}^{\prime}\right), 1.93\left(1 \mathrm{H}, \mathrm{m}, \mathrm{H}-5_{\mathrm{eq}}^{\prime}\right)$, $2.10\left(1 \mathrm{H}, \mathrm{m}, \mathrm{H}-4_{\mathrm{eq}}^{\prime}\right), 2.32\left(1 \mathrm{H}, \mathrm{dtd}, J 1.5,5.4\right.$ and 14.6, $\left.\mathrm{H}-6_{\mathrm{ax}}^{\prime}\right)$, $2.35(1 \mathrm{H}, \mathrm{t}, J$ 2.7, H-9') $2.43(1 \mathrm{H}, \mathrm{dd}, J 2.7$ and 17.0, H-7'a), 2.54 
$\left(1 \mathrm{H}, \mathrm{dd}, I 2.7\right.$ and $\left.17.0, \mathrm{H}^{\prime} \mathbf{7}^{\prime} \mathrm{b}\right), 2.59(1 \mathrm{H}, \mathrm{ddd}, J 5.9,10.1$ and 14.7, $\left.\mathrm{H}-6_{\mathrm{eq}}^{\prime}\right), 4.05\left(1 \mathrm{H}, \mathrm{dd}, J 2.9\right.$ and $\left.5.8, \mathrm{H}-3^{\prime}\right) ; \delta_{\mathrm{C}}\left(125 \mathrm{MHz} ; \mathrm{D}_{2} \mathrm{O}\right.$; $\left.\mathrm{CCl}_{4}\right) 19.70\left(\mathrm{Me}_{\mathrm{ax}}\right), 20.21\left(\mathrm{C}-5^{\prime}\right), 22.15\left(\mathrm{C}-7^{\prime}\right), 26.98\left(\mathrm{C}-4^{\prime}\right), 37.15$ $\left(\mathrm{C}-6^{\prime}\right), 52.98\left(\mathrm{C}-2^{\prime}\right), 71.45\left(\mathrm{C}-9^{\prime}\right), 75.39\left(\mathrm{C}-3^{\prime}\right), 81.25\left(\mathrm{C}-8^{\prime}\right), 218.95$ $\left(\mathrm{C}-1^{\prime}\right)$.

Enantiomeric excess and absolute configuration of $(S, S)-(+)-3$ were determined by chiral GC ( $>99 \%$ ee) and literature comparison respectively.

Synthesis of $\left(S^{*}, S^{*}\right)-( \pm)-3-h y d r o x y-2-m e t h y l-2-(2-$ propynyl)cyclohexan-1-one, $( \pm)-3$

To a solution of 2-methylcyclohexan-1,3-dione ( $2.3 \mathrm{~g}, 15.9 \mathrm{mmol})$, in a $1.0 \mathrm{~mol} \mathrm{l}^{-1} \mathrm{NaOH}$ solution $(17.5 \mathrm{ml})$ at room temperature, propargyl bromide $(2.8 \mathrm{~g}, 23.8 \mathrm{mmol})$ was added. The reaction mixture was stirred for 1 day at room temperature. Water was then added to the reaction mixture and it was extracted with ethyl acetate. The organic layer was dried over $\mathrm{Na}_{2} \mathrm{SO}_{4}$, filtered and evaporated under reduced pressure. The residue was purified by column flash chromatography, eluting with 2:1 hexane: ethyl acetate, yielding 2-methyl-2-(2-propynyl)cyclohexan-1,3-dione (2.1 g, $80 \%$ yield).

To a solution of 2-methyl-2-(2-propynyl)cyclohexan-1,3-dione (328 mg, $2 \mathrm{mmol})$, in methanol $(4 \mathrm{ml})$ at $0{ }^{\circ} \mathrm{C}, \mathrm{NaBH}_{4}(19 \mathrm{mg}$, $0.5 \mathrm{mmol}$ ) was slowly added. The mixture was stirred vigorously for $20 \mathrm{~min}$ and poured over $5 \% \mathrm{HCl}$. The methanol was evaporated before extraction with ethyl acetate was performed. The organic layer was dried over $\mathrm{Na}_{2} \mathrm{SO}_{4}$, filtered and evaporated under reduced pressure. The residue was purified by column flash chromatography, eluting with $4: 1$ hexane: ethyl acetate, yielding $( \pm)-\left(S^{*}, S^{*}\right)-\mathbf{3}(162 \mathrm{mg})$ and $( \pm)-(R, S)-3 \mathbf{a}(163 \mathrm{mg})$, with total yield of $98 \%$. Spectral data were identical to those of enantiomerically pure (+)-3.

\section{Acknowledgements}

The authors are indebted to CNPq (Conselho Nacional de Desenvolvimento Científico e Tecnológico) and FAPESP (Fundação de Amparo à Pesquisa do Estado de São Paulo) for financial support and for fellowships to A. L. J. and G.J. A. C. We also acknowledge Domingos S. Miranda and Regina A. C. Gonçalves for helping with the setup of the biocatalysis reactions.

\section{REFERENCES}

1. (a) Liu J, Coffey H, Detlefsen DJ, Li Y, Lee MS. J. Chromatogr. A 1997; 763: 261. (b) Endresz G, Chankvetadze B, Berghenthal D, Blaschke G. J. Chromatogr. A 1996; 732: 133. (c) Atuaki Z, Desiderio C, Mannina L, Fanali S. J. Chromatogr. A 1998; 817: 91. (d) Chankvetadze B, Schult G, Berghenthal D, Blaschke G. J. Chromatogr. A 1998; 798: 315.
2. (a) Endresz G, Chankvetadze B, Berghenthal D, Blaschke G. J. Chromatogr. A 1995; 717: 245. (b) Chankvetadze B, Endresz G, Schulte G, Berghenthal D, Blaschke G. J. Chromatogr. A 1996; 732: 143. (c) Zubiaur M, Jaime C. J. Org. Chem. 2000; 65: 8139.

3. (a) Stejskal EO, Tanner JE. J. Chem. Phys. 1965; 42: 288. (b) Stilbs P. Prog. Nucl. Magn. Reson. Spectrosc. 1987; 19: 1.

4. (a) Johnson CS Jr. In Encyclopedia of NMR, vol. 3, Grant DM, Harris RK (eds). John Wiley: New York, 1996; 1626. (b) Johnson CS Jr. Prog. Nucl. Magn. Reson. Spectrosc. 1999; 34: 203.

5. Gafni A, Cohen Y, Kataky R, Palmer S, Parker D. J. Chem. Soc., Perkin Trans. 2 1998; 19.

6. Morris KF, Johnson CS Jr. J. Am. Chem. Soc. 1992; 114: 3139.

7. Morris KF, Stilbs P, Johnson CS Jr. Anal. Chem. 1994; 66: 211.

8. (a) Chen A, Wu D, Johnson CS Jr. J. Phys. Chem. 1995; 99: 828. (b) Chen A, Shapiro M. J. Am. Chem. Soc. 1999; 121: 5338. (c) Lin M, Jayawickrama DA, Rose RA, DelViscio JA, Larive CK. Anal. Chim. Acta 1995; 307: 449. (d) Johnson CS Jr. J. Magn. Reson. A 1993; 102: 219. (e) Skinner PJ, Blair S, Kataky R, Parker D. New J. Chem. 2000; 24: 265. (f) Sánchez M, Parella T, Cervelló E, Jaime C, Virgili A. Magn. Reson. Chem. 2000; 38: 925.

9. Szejtli J, Lipták A, Jodál I, Fügedi P, Nánási P, Neszmélyi A. Starch/Stärcke 1980; 32: 165.

10. (a) Mori K, Mori H. Org. Synth. 1989; 68: 56. (b) Brooks DW, Mazdiyasni H, Grothaus PG. J. Org. Chem. 1997; 52: 3223.

11. (a) Porto ALM, Cagnon JR, Marsaioli AJ, Eguchi SY, Manfio GP. Chemosphere 1999; 38: 2237. (b) Cagnon JR, Marsaioli AJ Riatto VB, Pilli RA. Chemosphere 1999; 38: 2243.

12. (a) Laverde A Jr, Miranda DS, Conceição GJA, Schirner H, Pilli RA, Meijere A, Marsaioli AJ. J. Braz. Chem. Soc. 1999; 10: 293. (b) Feringa BL, Smaardijk A, Wynberg H. J. Am. Chem. Soc. 1985; 107: 4798

13. (a) Job P. Ann. Chim. 1928; 9: 113. (b) Djedaini F, Lin SZ, Perly B, Wouessidjewe D. J. Pharm. Sci. 1990; 79: 643.

14. Benesi HA, Hildebrand JH. J. Am. Chem. Soc. 1949; 71: 2703.

15. Scott RL. Rec. Trav. Chim. 1956; 75: 787.

16. Borges RB, Laverde A Jr, Porto ALM, Marsaioli AJ. Spectrosc. Int. I. 2000; 14: 203

17. Bax A, Grzesiek S. In Encyclopedia of NMR, vol. 5, Grant DM, Harris RK (eds). John Wiley: New York, 1996; 4157.

18. Pelta MD, Barjat H, Morris GA, Davis AL, Hammond SJ. Magn. Reson. Chem. 1998; 36: 706.

19. Wu D, Chen A, Johnson CS Jr. J. Magn. Reson. A 1995; 115: 123.

20. Rymdén R, Carlfors J, Stilbs P. J. Incl. Phenom. 1983; 1: 159.

21. Gounarides JS, Chen A, Shapiro MJ. J. Chromatogr. B 1999; 725: 79. 